\title{
THE MANAGEMENT OF VIOLENT OR POTENTIALLY VIOLENT PATIENTS*
}

\section{Comments on the Confederation of Health Service Employees' Report}

\section{Introduction}

The COHSE Special Working Party Report was a response to guidance issued by the Department of Health and Social Security in $H C(76)$ I 1 entitled The Management of Violent or Potentially Violent Hospital Patients, which the Confederation considered inadequate. The DHSS Circular had been prepared after protracted discussions with the Royal College of Nursing (Ren) and the Royal College of Psychiatrists. The COHSE Report extends beyond the issue of the management of violence, and we did not consider all the points put forward in the document (see page 124, para. 2 and page 125, para. 5 below).

Recalling the discussions of the early drafts of the advice which this College and the Ren prepared to assist the DHSS in its task, the difficulties are appreciated of trying to be comprehensive without being over-inclusive and yet helping a nurse to make the right decision in a difficult situation. It is therefore acknowledged that while some of the text of the COHSE Report is contradictory and inaccurate and elsewhere views are based on unwarranted assumptions, for example in the description of signs and symptoms which may precede a violent episode and the causes of aggression (paras. 60.1 61.1), it will have achieved its objective if it is really understood by COHSE members. With hindsight it was perhaps unfortunate, in view of the high proportion of nursing staff working in psychiatric hospitals who are members of COHSE, that the DHSS chose to consult only this College and the Rcn before preparings its Circular. In addition, the Ren has since (1977) become a certificated independent Trade Union.

\section{Violent Incidents and Staffing Levels}

The doubts and anxieties of nursing staff in psychiatric hospitals throughout the country are understandable in the present climate of financial restraint, shortages of staff and poor recruitment, and the increasing number of Committees of Inquiry. To assert, however, that shortages of resources of both manpower and finance are a direct cause of violence in hospital patients (para. 4.1) is hard to substantiate. It is difficult to establish, as the Report claims (paras. $2.3,2.4)$, that there has been an increase in violent episodes, and it is likely that the apparent increase is due to increased reporting of such episodes. However, in making this observation the College does not wish to minimize the concern which is felt about the present number of violent incidents but wishes to point out the difficulty in making valid comparisons. Indeed, the Report appears later to contradict itself in its statement that "because of the comparatively low incidence of violence, the skills used in dealing with the violent situation are rarely learned. In cases where more experienced nurses have the skills, they frequently refrain from exercising them, as they feel a lack of confidence ...' (para. 11.3). This state of affairs is attributed (without corroborative evidence) to failure of medical staff to investigate complaints fully and a tendency to accept the patient's word 'far too readily' (para. 11.2). (Liaison between professional staff is dealt with more fully later on.)

The College agrees that there is less likelihood of a dangerous or disruptive situation arising if the patients can be kept occupied, and the recommendations concerning the provision of occupational and industrial therapy on the wards, as well as in separate departments, are commended (para. 9.3).

The Confederation's concern about staffing levels (para. 4) is appreciated, and their recommended overall staff to patient ratio of $1: 1$ (which includes allowances for 24-hour, year-round cover, and for leave and sickness) (para. 8.1) is endorsed. Also endorsed is its recommendation that 60 per cent of the nursing staff should be trained, with the additional proviso that the remaining $4^{\circ}$ per cent should be nurses in training.

\section{Liaison between Professions}

COHSE accepts that clinical care is the responsibility of the consultant psychiatrist (para. 6.3), but complains that there is a lack of liaison between the professions and that the policies for day-to-day care of patients are formulated by medically dominated psychiatric divisions (para. 6.1).

In paragraph 10 it recommends the establishment of a multidisciplinary group, suggests its composition and outlines its responsibilities.

- Prepared by a Working Party of the Public Policy Committee and approved by the Executive and Finance Committee, 10 March 1978. The Working Party was chaired by Dr W. A. Heaton-Ward. The Forensic Psychiatry Section was represented by Dr Paul Bowden and the Mental Deficiency Section by Dr E. W. Shepherd. Dr J. E. Glancy and Dr John Gunn, who were advisers to the COHSE Special Working Party, attended as observers. Dr C. P. Seager submitted written comments on behalf of the Nursing Sub-Committee of the Education Committee. 
The complaint (already briefly mentioned above) that nursing staff often feel that medical staff are too remote and do not give the support that is required is probably justified. It is apparently a common complaint that some consultants show little interest in the problems faced by nursing administration with regard to difficult patients and that many hospitals operating policies of greater freedom for their patients have failed to produce rules to which informal patients must conform. Even where such rules have been applied to informal patients the support given by the nursing and medical administration to the nurse on the ward still leaves much to be desired (paras. 11.2, 11.4 ).

Some wards in some hospitals do not see a doctor from one month to another. The St Augustine's Hospital Inquiry emphasized this point. This could be due to inadequate staffing levels. An increasing commitment in the community (especially in mental handicap) exacerbates the problem. The College regrets that there are grounds for these complaints and hopes that every effort will be made to remedy the situation.

The Confederation has made recommendations in paragraph 17 about the liaison between general practitioners and the psychiatric community nursing service. It would be inappropriate for the College to comment on this part of the Report. However, the College felt there was a need for COHSE to clarify its statement in para. 17.2 which seemed to imply that nurses were members of the medical profession. ('We have already stressed the need for the rapid expansion of the community psychiatric nursing services. Many AHAs have still to set up such services. We stress here the need for community psychiatric nurses to be involved in the psychiatric emergency, and for each Area to ensure that the service is informed of all psychiatric emergencies. This should be done by involving the community psychiatric nursing service in the Area Psychiatric Committee (see para. 20); this would be an invaluable asset in the psychiatric emergency, by making available an experienced member of the medical profession with a knowledge of psychiatry'.)

\section{In the Psychiatric Hospital}

The Confederation recommends the establishment of one special care unit (for difficult and violent patients) under the control of one consultant in each large psychiatric hospital, and promises to issue guidelines on the setting up and staffing of such units in the near future (para. 7.6). (These units should not be confused with Regional Secure Units or with special care units for profoundly mentally-handicapped patients.) The Confederation argues that the establishment of these units would help to counteract the problems arising from the open door policy and from the implementation of the recommendations of the Salmon Committee. The present division into separate units within a hospital, each attempting to provide a total service for its catchment area, means that difficult and possibly violent patients may be encountered on a number of wards where present staffing levels are inadequate to deal with any incidents (paras. 7.1, 7.2). As COHSE emphasizes, in the past psychiatric hospitals usually had two admission wards, so it was possible to concentrate skilled staff in these two areas where most difficulties were likely to arise, and COHSE claims that the present system could lead to more ward doors being locked, thereby depriving a number of patients of their liberty (para. 7.4).

The establishment of a special care unit would appear to fill the need for an area in each large psychiatric hospital where difficult patients could be assessed on admission and where in-patients could be referred temporarily or in an emergency if they were seriously disturbing ward routıne and other patients. The proposal that the special care unit should be the responsibility of one consultant is supported, as it is considered that the positive guidance and support which the staff of such a unit need is more likely to be achieved if they can relate to one person. However, this would need to be determined locally.

In paragraph 7.2 COHSE refers to the admission of 'psychopaths' and in paragraph 7.7 quotes the conclusion of the Butler Committee on Mentally Abnormal Offenders that 'the great weight of evidence presented to us tends to support the conclusion that psychopaths are not, in general, treatable, at least in medical terms'. The COHSE Report goes on to recommend that 'such patients should not be admitted (to mental illness hospitals which do not have special facilities for their care) except possibly as a short-term expedient to deal with a crisis'. The College supports this recommendation, but is concerned about the vague use of the term 'psychopath' in this context; this is in conflict with the definition in the Mental Health Act 1959, which states that 'psychopathic disorder' means a persistent disorder or disability of mind (whether or not including subnormality of intelligence) which results in abnormally aggressive or seriously irresponsible conduct on the part of the patient and requires or is susceptible to medical treatment (Part I, Section 4(4)). The term should be used only in the legal sense as set out in the Act.

COHSE notes the growing tendency of staff in psychiatric hospitals to refuse to accept the more difficult patients 'with the result that there are an 
increasing number of people in need of psychiatric care who are at present in prisons and other institutions' (para. 7.2).

The Reports of Committees of Inquiry underline COHSE's statement that the obvious conclusion is that psychiatric hospitals are understaffed, with insufficient trained nursing staff in relation to students and pupils to meet the needs of contemporary psychiatric care (para. 7.5).

COHSE has sometimes been accused of refusing admission to hospital of difficult patients either from the Courts or because of their previous history. In this Report COHSE advises its members that '(they) should not attempt to prevent the admission of a patient to hospital as such, but should make direct representations to the employing authority if in their opinion that patient constitutes a danger, if there are inadequate facilities and if staffing levels are insufficient to enable them to give proper care to safeguard them from any dangers which could exist, and should reserve the right to refuse to nurse the patient if adequate facilities are not available' (Appendix III).

COHSE recommends the proper training of staff to assist in the management of the violent patient and in particular how to avoid precipitating violence (para. 58.1). The College endorses COHSE's advice that a difficult or deteriorating situation should be reported to the senior nurse on duty or to a nursing officer, but does not agree with the recommendations in paragraph 65.2 that every possible attempt should be made to avoid physical contact until assistance is available; this may be desirable, but may not be feasible in practice in an emergency situation.

The College questions the COHSE recommendation that when a particular nurse and a particular patient are totally incompatible the situation should be discussed openly by the ward multidisciplinary group. Depending, of course, upon the composition of the team this could be an unjustifiably traumatic experience for the nurse, albeit of benefit to other members of staff in helping them to cope professionally (para. 63.4). Total incompatibility is more likely to involve a nurse than other staff simply because the nurse is generally on the ward for much longer periods of time than any other member of the team.

In paragraph 9.6 it is recommended that patients refusing to comply with the rules necessary for good ward management should be discharged. No distinction is made here between detained and informal patients who fail to behave in a reasonable manner and who seriously disrupt the ward routine. It is important to recognize that where the unreasonable behaviour is a symptom of the illness and there- fore part of the reason for being in hospital it may be inappropriate to discharge such an individual. The College has interpreted a recommendation in paragraph 78.3 that an informal patient who shows a likelihood of being a danger to himself or others should be discharged as applying only when the consultant concerned is unwilling to agree to the compulsory detention of the patient.

One of the nurses' chief anxieties concerns their right to search and take away patients' possessions. The Mental Health Act leaves a degree of uncertainty about nurses' rights in respect of informal patients. Section 141 provides legal cover for action taken with regard to detained patients, although it is noted that this will be restricted if the recommendations of the Interdepartmental Committee on the Review of the Mental Health Act, which the College has already endorsed, are accepted (News and Notes, January 1977, pp 9-1 7). Whatever the correct interpretation of the various Sections of the Act, the College feels strongly that nursing staff must have the necessary legal authority to run a ward in a reasonable manner.

\section{In the Community}

The Report highlights many difficulties which arise in the community, to which perhaps insufficient attention has been given in the past; for example, in the transportation of patients to hospital, the training of ambulance crews and the facilities in emergency and accident departments. COHSE recommends ( 1 ) that all ambulance staffs should be trained; (2) that patients being admitted to hospital should always be accompanied by two people in addition to the driver; (3) that patients should be transferred in vehicles with separate driving compartments (London-type taxi). The College would support these recommendations (paras. 19.1 to 19.5), although some of them may prove difficult to implement.

One of the most disturbing areas dealt with in the Report is the transportation of patients to hospital by community nursing staff (paras. 12.5, 12.6). The College endorses the recommendation that community nurses doing this should be provided with trained escorts. The College recommends also that the employing authorities should provide adequate insurance cover for nurses using their own vehicles to cover any incidents which may occur while they are transporting patients.

The comments on general practitioner service (paras. I6.1 to 17.4 ) have been noted, but they are, as stated above, matters for discussion with the Royal College of General Practitioners. This College, however, would wish to assist in the provision of postgraduate courses for general practitioners were this suggestion to be taken up (para. 16.5). 
Paragraphs 18.1 to 18.3 discuss the present training of generic social workers and its shortcomings. The College supports the recommendations for in-service psychiatric training of social workers.

Area Psychiatric (Multidisciplinary) Committees are recommended in the Report, at Area level, to draw up and monitor policies for dealing with the psychiatric emergency (para. 20.1). The College would prefer this to remain a responsibility of the AHA, which should also be responsible for ensuring that psychiatric beds are available in an emergency.

A Crisis Intervention Team in each Health District is a very laudable recommendation (para. 21.1). The College has reservations, however, about the possibility of implementing this recommendation.

\section{The Power to Treat}

The treatment of the unwilling patient has been the subject of much debate, especially since the publication of the St Augustine Report, and the COHSE Report underlines the difficult position of nursing staff. The Confederation has taken legal advice, and as a result has recommended that 'compulsory treatment without consent, whether "Section" patients or informal, is probably unlawful; and members are advised that under no circumstances should they give or participate in such treatment, and treatment here includes ordinary medication' (para. 72.5). However, this advice appears to be in direct conflict with that in paragraph 77.2, in which it is advised that 'the patient (informal) should be detained under Section 25 or 26 of the Mental Health Act so that any required treatment may be given'.

The College notes the recommendation in paragraph 69.3 that COHSE members should not use mechanical restraint under any circumstances, and is concerned that this might be interpreted as including, for example, the splinting of limbs of a severely subnormal patient to prevent selfmutilation.

The DHSS has recently suggested that consultants should try to avoid giving trcatment entailing irreversible consequences or high risks to the patient if consent cannot be obtained, and that it may also be advisable to seek a further medical opinion where other treatments involving substantial risks are contemplated. However, this advice is qualified by stating that the doctor would be likely to have a valid defence in law, whether or not the patient was detained under the Mental Health Act, if he administered treatment without consent to meet an emergency or to prevent an emergency which would otherwise be likely to arise. This would not include the giving of treatment more drastic than the needs of the emergency justified.

Hitherto doctors have had to use their own judgement, as this question has not been tested at law.

The recommendations of the Davies Committee on Hospital Complaints Procedure, however, did imply that the Mental Health Act would have to be amended. The College understood the intentions of the Committee to apply to the imposition of medical treatments and in particular to irreversible and controversial treatments. The College recommended that it should be mandatory to obtain two medical opinions to treat patients compulsorily where ECT or leucotomy (and allied brain surgery) was considered. ECT was excepted when used as an emergency procedure. The written agreement of the nextof-kin was to be obtained where possible. This advice and these consent procedures have been incorporated in the College's comments on the Interdepartmental Committee's Review of the Mental Health Act, 1959 and in the Memorandum on the Use of ECT, British Journal of Psychiatry (1977), 131, 26172. There remains a dilemma for medical practice until such time as either the interpretation of the present Act is clarified or the relevant clause amended.

The COHSE interpretation would appear to make it impossible to treat patients in the new Secure Units, and hospitals would become even more reluctant to receive patients from Courts. Forensic psychiatry, perhaps more than any other branch of the specialty, would be affected by such proposals.

There is a very real need to clear up the confusion which exists for all those directly involved in the treatment of formal and informal patients. The Confederation has asked for an urgent redefinition (para. 72.1), and it would appear desirable that Parliament should act without waiting for the White Paper, as new legislation on the whole Act will obviously not be achieved in the near future.

The climate of public opinion has changed considerably since the passing of the 1959 Act. There is no longer an acceptance that members of the medical and nursing professions will act in good faith. There is now a very real threat of litigation which naturally places a great strain on interprofessional relationships, and the nursing profession in particular seems no longer reassured of the support of psychiatrists. The College regrets that this feeling seems justified in many cases because of the doctor's unwillingness or failure to communicate his intentions to the staff. One of the results of these hardening attitudes is the inevitable narrower interpretation of the provisions of the 
Mental Health Act, with a consequent increase in the number of patients formally detained.

As stated in our Introduction, while not accepting all the arguments, the College considers that the COHSE Report has made a valuable contribution to the debate which will continue until all the different views have been crystallized and either ratified or rejected by Parliament.

The College is concerned that much of what is intended as guidance in the Report will be regarded by many as a statement of the considered policy of COHSE.

\section{THE ROLE, RESPONSIBILITIES AND WORK OF THE GHILD AND ADOLESGENT PSYGHIATRIST*}

\section{Introduction}

This document, produced by the Child and Adolescent Psychiatry Section of the College, is aimed at administrators, trainees considering entering the specialty, and colleagues in other disciplines. Its purpose is to describe the role of child and adolescent psychiatrists today, who work largely as part of a multidisciplinary team and may be based in a hospital or in the community. There is increasing emphasis on community work: assessment, treatment and preventive work is carried out with children and their families in close liaison with mainly non-medical colleagues. Such multidisciplinary teamwork has many advantages, but presents delicate problems in ethics and organization. In what follows "child psychiatrist' will be generally used to mean 'child and adolescent psychiatrist'.

1. Training and Appointment of a Consultant Child and/or Adolescent Psychiatrist

A consultant child psychiatrist is a qualified medical practitioner. It is best for experience in neurology and paediatrics to precede general psychiatric training, which is a three-year preparation for the examination for the Membership of the Royal College of Psychiatrists (M.R.C.Psych.). General psychiatric training provides experience in diagnosis and managment of adult psychiatric patients in different settings and using a variety of therapeutic skills. At this stage, the trainee is introduced to the specialties, including child psychiatry, and some may have a personal psychoanalysis. Specialist training in child psychiatry starts at senior registrar level. Training is both academic and clinical. The trainee's work, supervised by a consultant child psychiatrist, develops so that by the end of training he should be capable of leading a multidisciplinary child psychiatric team and organizing a clinical service.
Appointment to the post of consultant child psychiatrist in the National Health Service is by open competition by an Appointments Committee, including others in the same field and representatives from Universities and Health Authorities. An assessor from the Royal College of Psychiatrists advises on the standard of training of the applicants. A guideline for approval for training programmes in child and adolescent psychiatry has been issued by the Joint Committee on Higher Psychiatric Training (I).

\section{The Responsibilities of a Consultant Child and/or Adolescent Psychiatrist}

(i) General

A consultant child psychiatrist in the NHS has clinical autonomy, as do consultants in other fields, with consequent legal, professional and moral obligations. The consultant is usually based in an NHS hospital and/or a Child Guidance Clinic run by a Local Education Department or Area Health Authority. Many child psychiatrists spend much of their time in a wide variety of settings where disturbed children and adolescents are to be found. Collaboration and consultation occurs with many other professions as well as other branches of medicine. Since the work necessitates much closer involvement in a multidisciplinary team than is the case in other branches of medicine, problems concerning clinical responsibility have arisen and are discussed in Section 5 .

(ii) Clinical Responsibilities

The clinical services include:

(a) diagnostic assessment;

(b) treatment of children and families;

* Approved by Council 31 March 1978. 